\title{
Modeling on Health Status of Cable lines
}

\author{
Li Kewen ${ }^{1, ~ a, ~ L i ~ S h a n ~}{ }^{2, b}$ and Ou Shifeng ${ }^{3, c}$ \\ ${ }^{1}$ Electric Power Research Institute, Minzhu road 6-2, Nanning, Guangxi China \\ ${ }^{2}$ Electric Power Research Institute, Minzhu road 6-2, Nanning, Guangxi China \\ ${ }^{3}$ Electric Power Research Institute, Minzhu road 6-2, Nanning, Guangxi China \\ aLi_kw.sy@gx.csg.cn, bi_s.sy@gx.csg.cn, ${ }^{\circ} \mathrm{O} u \_s f . s y @ g x . c s g . c n$
}

Keywords: Cable line; State evaluation; Maximum eigenvalue; Grey correlation

Abstract. This paper introduces the state of cable lines assessment model, analyzes and describes the establishment of evaluation index system, state variable weight calculation and determination of the final comprehensive evaluation results. Due to that maintenance system reasonable directly influences reliability level, modeling on the health status of cable lines is significant for maintenance, fault prediction and distribution management.

\section{Introduction}

Compared with overhead transmission lines, cable lines own many advantages: high power supply reliability, small occupation area and beneficial to city beautification. However, with the large-scale use of cable lines, accidents also frequently occurred and was located difficultly. Especially cable lines in high voltage grade, once accident occurred, long time must be taken to outage maintenance, causing great economic losses. Thus, research on the health status of cable lines is significant.

\section{Computing weight based on largest eigenvalue method}

Establishing state evaluation index system of cable lines. To implement the accurate and comprehensive assessment for the health status of cable line, state variables which can reflect running state of cable line is indispensable. Combing a set consists of test information, operation information, and inspection tour information, a feasible state evaluation index system could be established [1].This index system includes two levels, as shown in Fig.1

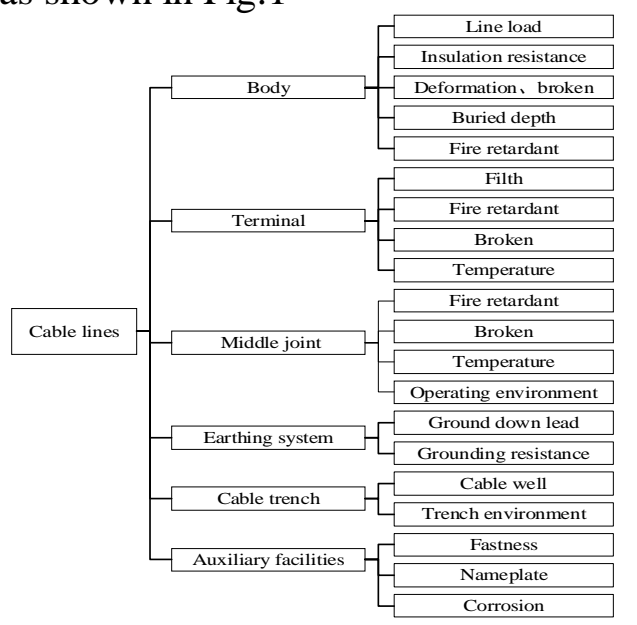

Fig.1 evaluation index system of cable lines

Calculating the weight of state variables by AHP.The principle of Analytic hierarchy process (AHP) is dividing a complex problem into several factors. According to the mutual correlation and subordinate relations, these factors could constitute orderly ladder hierarchy and thus form a Multi-level evaluation model. By inter comparison, The relative importance of various factors can be determined [2], then on the basis of physical truth, The weight coefficient of various factors will be calculated. This method bases on specialists' subjective cognition on the importance of every various 
indicators, which is persuasive. The methods to calculate weight of AHP includes Geometric mean method, arithmetic mean method, characteristic vector method and least square method [3].

This article adopts the theory of analytic hierarchy process (AHP), In accordance with the principle of grade $1 \sim 9$ scale (as shown in Table 1) to determine the relationship of importance between the two elements on the same level, and thus getting the judgment matrix. Through the inter comparison between the primary indexes, the primary level judgment matrix and weight vector can be computed, and as shown in Table1.

Table 1 the primary level judgment matrix and weight vector

\begin{tabular}{|l|l|l|l|l|l|l|}
\hline first grade & Body & $\begin{array}{l}\text { Termin } \\
\text { al }\end{array}$ & $\begin{array}{l}\text { The middle } \\
\text { joint }\end{array}$ & $\begin{array}{l}\text { Earthing } \\
\text { system }\end{array}$ & $\begin{array}{l}\text { Cable } \\
\text { trench }\end{array}$ & $\begin{array}{l}\text { Auxiliary } \\
\text { facilities }\end{array}$ \\
\hline Body & 1 & $5 / 4$ & $5 / 4$ & $5 / 2$ & $5 / 3$ & $5 / 3$ \\
\hline Terminal & $4 / 5$ & 1 & 1 & 2 & $4 / 3$ & $4 / 3$ \\
\hline Middle joint & $4 / 5$ & 1 & 1 & 2 & $4 / 3$ & $4 / 3$ \\
\hline $\begin{array}{l}\text { Eartihing } \\
\text { system }\end{array}$ & $2 / 5$ & $1 / 2$ & $1 / 2$ & 1 & $2 / 3$ & $2 / 3$ \\
\hline Cable trench & $3 / 5$ & $3 / 4$ & $3 / 4$ & $3 / 2$ & 1 & 1 \\
\hline $\begin{array}{l}\text { Auxiliary } \\
\text { facilities }\end{array}$ & $3 / 5$ & $3 / 4$ & $3 / 4$ & $3 / 2$ & 1 & 1 \\
\hline weight & 0.2448 & 0.1958 & 0.1958 & 0.0979 & 0.1328 & 0.1328 \\
\hline
\end{tabular}

The computational formula of CI (consistency index) is:

$$
C I=\frac{\lambda_{\max }-n}{n-1}
$$

$\lambda_{\max }$ represents the eigenvalue of maximum of judgment matrix, $\mathrm{n}$ represents the dimensions .

The computational formula of CR (consistency ratio) is:

$$
C R=\frac{C I}{R I}
$$

When $\mathrm{CR}<0.1$, The consistency of judgement matrix can be received. In this article, we can get the result that $\mathrm{CR}$ of judgment matrix is 0.0047 , meet the requirement of consistency.

In a similar way, Based on expert scoring, judgment matrix of secondary index can be established, The weight of state variables under the secondary index is shown as Table 2:

Table 2 the weight of state variables under the secondary index

\begin{tabular}{|l|l|}
\hline Component & The weight of state variables under the secondary index \\
\hline Body & {$[0.25,0.25,0.1666,0.1667,0.1667]$} \\
\hline Terminal & {$[0.2222,0.2222,0.2222,0.3334]$} \\
\hline The middle joint & {$[0.3334,0.2222,0.2222,0.2222]$} \\
\hline Earthing system & {$[0.5,0.5]$} \\
\hline Cable trench & {$[0.1667,0.1667,0.3333,0.3333]$} \\
\hline Auxiliary facilities & {$[0.5,0.25,0.25]$} \\
\hline
\end{tabular}

\section{Modeling Based on the theory of fuzzy theory}

The establishment of the evaluation set.In this article, the state of cable lines is divided into five levels, $\mathrm{V}=\{$ dangerous abnormal、suspicious、normal、 favorable $\}$. Favorable state means that all state variables meet the standard or are away from abnormal outliers. Normal state means that the state variables of equipment are normal or reliability of individual parameters decrease slightly. Suspicious state means that several state variables fail to meet the standard but equipment still operate normally. Abnormal state means that the state variables of equipment is close to or reach outliers according to discipline, failure would occur or had occurred, but in the short term the accident would not happen. 
Dangerous state means that the state variables of equipment are beyond outliers or seriously abnormal, accident may occur at any time[4].

Standard for evaluation. Relative inferiority degree (RID) represents the ratio of the current state to the attentive state [5]. State variables can be divided into two categories, namely qualitative indexes and quantitative indexes. For qualitative state variables, expert experience method can be employed. According to the degree of influence to state of the equipment, higher scores mean the better running status. Linear piecewise function can be used to quantify qualitative indicators.Referring to the relevant equipment factory national standards and enterprise standards, the proper function can be drawn for scoring. Quantitative indicators can be divided into positive and reverse indicators. Positive indicators have the characteristics that the greater the parameter values, the more optimal performance, such as insulation resistance etc. Negative indicators have the characteristics that the smaller the parameter values, the more optimal performance, such as grounding resistance.

Subordinate functions and subordinate matrix. The membership matrix of cable lines reflects the degree that state variables attach to each evaluation set. The degree of subordinate membership could be determined by subordinate functions. Whether the choice of subordinate functions is reasonable or not, is directly related to the accuracy of the final evaluation results [6]. Combination of triangular and trapezoidal distribution function is simple and accuracy.

Domain of subordinate functions is $(0,1)$, Subordinate functions are shown as follows:

Subordinate function in favorable state:

$$
\mu(x)=\left\{\begin{array}{cc}
1 & x \geq 95 \\
0.1 x-8.5 & 85 \leq x \leq 95 \\
0 & x \leq 85
\end{array}\right.
$$

Subordinate function in normal state:

$$
\mu(x)=\left\{\begin{array}{cc}
-0.1 x+9.5 & 85 \leq x \leq 95 \\
0.1 x-7.5 & 75 \leq x \leq 85 \\
0 & \text { others }
\end{array}\right.
$$

Subordinate function in suspicious state:

$$
\mu(x)=\left\{\begin{array}{cc}
-0.1 x+8.5 & 75 \leq x \leq 85 \\
5 x-1 & 65 \leq x \leq 75 \\
0 & \text { others }
\end{array}\right.
$$

Subordinate function in abnormal state:

$$
\mu(x)=\left\{\begin{array}{cc}
-0.1 x+7.5 & 65 \leq x \leq 75 \\
0.1 x-5.5 & 55 \leq x \leq 65 \\
0 & \text { others }
\end{array}\right.
$$

Subordinate function in dangerous state:

$$
\mu(x)=\left\{\begin{array}{cc}
1 & x<50 \\
-1 / 15 x-13 / 3 & 50 \leq x \leq 65 \\
0 & \text { others }
\end{array}\right.
$$

Introducing grey correlation theory to determine the final state of cable line.The basic ideology of grey correlation degree is quantifying correlation degree according to the curve of similar degree of correlation. Set reference number series is $\left\{X_{0}\right\}$, compared number series is $\left\{X_{i}\right\}$, denoted as:

$$
\begin{gathered}
\left\{X_{0}\right\}=\left\{X_{0}(1), X_{0}(2), \cdots X_{0}(n)\right\} \\
\left\{X_{i}\right\}=\left\{X_{i}(1), X_{i}(2), \cdots X_{i}(n)\right\}
\end{gathered}
$$

Thus definite:

$$
\xi_{i}(k)=\frac{M_{\text {min }}+0.5 M_{\text {max }}}{\Delta_{i}(k)+0.5 M_{\text {max }}}
$$


Which is correlation coefficient of reference sequence, and compared sequence at k point, Among them:

$$
\Delta_{i}(k)=\left|X_{0}(k)-X_{i}(k)\right|
$$

$\mathbf{M}_{\min }$ is smallest difference between two stages, $\mathbf{M}_{\max }$ is the biggest. The correlation degree is:

$$
r=\frac{1}{n} \sum_{1}^{n} \xi_{i}(k)
$$

Choosing five groups of reference number series correspond to five different clear judgments. favorable state is $[1,0,0,0,0]$, normal state is $[0,1,0,0,0]$, suspicious state is $[0,0,1,0,0]$, abnormal state is $[0,0,0,1,0]$, dangerous state is $[0,0,0,0,1]$.

\section{Analysis of examples}

Choosing the test and inspection data of a segment of cable line in Nanning power supply company as example. The type of this segment of cable line is LSN 10/3.1-3X9.5m.Based on the actual state of this segment of cable line, score of every part are as below:

Table 3 scores of every components

\begin{tabular}{|l|l|}
\hline Component & scores \\
\hline Body & {$[100,100,90,100,100]$} \\
\hline Terminal & {$[90,90,100,100]$} \\
\hline The middle joint & {$[100,100,100,100]$} \\
\hline Earthing system & {$[100,100]$} \\
\hline Cable trench & {$[100,100]$} \\
\hline Auxiliary facilities & {$[80,100,95]$} \\
\hline
\end{tabular}

The final comprehensive evaluation result is $[0.9669,0.0369,0,0,0]$. Thus the result that this section of the cable line operates well is convincing.

\section{Summary}

Grey correlation theory is very effective to assessment of the state of cable lines .

\section{Acknowledgments}

This work was supported by China Southern Power Grid Company Limited.

\section{References}

[1]Gao liang. Power distribution equipment and systems [M].Beijing: China Electric Power Press, 2009:65

[2]Yang dongsheng, Liu zixing, Zhang jing. Practical assessment method of distribution transformer condition based on largest eigenvalue method [J]. Power and energy,2014,35(3):271-274

[3]Deng xue, Li jiaming, Zeng haojian. Analysis and application research on weight calculation method by analytic hierarchy process (AHP) [J]. The practice and cognition of mathematics,2012,42(7):94-99

[4]Li rongjun. Operational research [M].Guangzhou: Technology press of South China university of,2002,196-199

[5]Liu yang. Assessment research on state of distribution transformer based on fuzzy comprehensive evaluation [D].Beiijng: North China Electric Power University,2013. 
[6]Liao ruijin, Yang lijun. Assessment method for the condition of power transformer insulation based on cloud theory[J].Transactions of China Electrotechnical Society,2012,27(5):13-20 